\title{
Análise descritiva das sequelas de acidentes de trânsito em Maceió, Alagoas
} Descriptive analysis of sequels deriving from traffic accidents in Maceió, Alagoas

Maria Luisa Duarte'1, Érica Carla Figueiredo de Souza², Paula Graziela Figueredo Bonfim²

Palavras-chave: Acidentes de trânsito Ferimentos e lesões Violência

\section{Resumo}

Os acidentes de trânsito determinam perdas precoces de vidas e sequelas com alto custo para a sociedade. Nenhum país se encontra salvo dessa tragédia e desse acúmulo de sofrimento, castigando de maneira muito particular aos jovens e trazendo consequências sociais e econômicas sumamente importantes. Essa pesquisa teve como objetivo fazer uma análise descritiva das sequelas físicas e funcionais decorrentes de acidentes de trânsito de vítimas atendidas pelo Instituto Médico Legal Estácio de Lima, Maceió/AL no ano de 2006. Consiste em um estudo epidemiológico transversal e retrospectivo. Foram analisados 377 laudos de lesões corporais, correspondentes ao período de janeiro a dezembro de 2006. Dos laudos analisados, 48,8\% das vítimas apresentaram sequelas. As vítimas investigadas caracterizaram-se por serem, em sua maioria, jovens e adultos jovens (56,8\%), do sexo masculino (76,9\%). 0 maior número de acidentes foi os automobilísticos (77,7\%). A maioria dos acidentes causou lesões graves (35\%), sendo que destas, $53 \%$ tiveram algum tipo de sequela. As lesões leves representaram $34,7 \%$ do total e as gravíssimas, 30,3\%. As sequelas foram agrupadas em quatro grupos: debilidade permanente (49\%), deformidade permanente (37\%) enfermidade incurável (6\%) e perda ou inutilização de membro, sentido ou função (8\%). Do ponto de vista da Saúde Coletiva, tal estudo contribuiu com mais dados epidemiológicos que possam servir de base para a avaliação da situação dos acidentes de trânsito e o planejamento das ações e dos serviços no sentido de buscar uma mudança das normas de segurança no trânsito, assim como alertar a população da importância da prevenção.

\section{Keywords: Abstract}

Traffic accidents Wounds and injuries

Violence

Traffic accidents determine early losses of lives and sequels with a high cost to society. № country is safe from this tragedy and this accumulation of suffering, punishing particularly the young people and bringing social and economic consequences extremely important. This research aimed to make a descriptive analysis of physical and functional sequels deriving to traffic accidents of victms attended by the Medico Legal Institute Estácio de Lima, Maceió/AL, Brazil in 2006. It consists of a cross and retrospective epidemiological study. Three hundred and seventy-seven reports of body injury were analyzed, covering the period January to December 2006. Of those reports, $48.8 \%$ of the victims presented sequels. The victims investigated were characterized by being, in the majority, youths and young adults (56.8\%), males (76.9\%). The highest number of accidents was the automobile (77.7\%). Most of the accidents had serious injuries (35\%), of which $53 \%$ of these had some kind of sequel. The light injuries accounted for $34.7 \%$ of the total and the serious, $30.3 \%$. The sequels were grouped into four groups: permanent weakness (49\%), permanent deformity (37\%) incurable disease (6\%) and loss or invalidity of the limb, sense or function (8\%). From the viewpoint of Collective Health, this study contributed to more epidemiological data that could serve as a basis for assessing the situation of traffic accidents and planning of actions and services in order to seek a change of safety standards in transit, as well as to warn the public of the importance of prevention.

\footnotetext{
Doutora em Patologia, graduada em Medicina pela Universidade Federal de Alagoas (UFAL), professora adjunta da Disciplina de Medicina Legal e Ética Médica da Universidade Estadual de Ciências da Saúde de Alagoas (UNCISAL), Maceió, AL, Brasil.

${ }^{2}$ Acadêmicas do $6^{\circ}$ ano da graduação em Medicina da UNCISAL, Maceió, AL, Brasil.

Endereço para correspondência: Maria Luisa Duarte, Rua Doutor Jorge Lima, 113 - CEP: 57010-382, Trapiche da Barra, Maceió/AL,
} Fone: (82) 3315-6776 - E-mail: maraluduarte@uol.com.br 


\section{Introdução}

Juntamente com a incorporação do automóvel no cotidiano das comunidades, surge um importante problema social: os acidentes de trânsito. No caso do Brasil, o trânsito é considerado um dos piores e mais perigosos do mundo. Os índices de acidentes são altíssimos, com um para cada lote de 410 veículos em circulação ${ }^{1}$. Agravando ainda mais a nossa situação, cerca de 30 mil pessoas morrem anualmente em acidentes de trânsito; $44 \%$ delas têm entre 20 e 39 anos de idade e $82 \%$ são homens. Além disso, mais de 100 mil são internadas devido às lesões adquiridas ${ }^{2}$.

$\mathrm{O}$ alto acometimento de pessoas jovens em acidentes de trânsito vem alterando até mesmo indicadores como a esperança de vida da população e os anos potenciais de vida perdidos (APVP) anulando anos ganhos com o combate a doenças. Nesse sentido, levando-se em conta os dados apresentados, pode-se considerar o trânsito e a violência que nele se manifesta como um problema de saúde pública que, se não enfrentado com eficiência, ocasiona e ocasionará danos irreparáveis à sociedade, aos indivíduos e ao Estado ${ }^{3}$.

A importante redução dos acidentes e mortes (ainda que transitória), a qual seguiu aprovação do novo Código Nacional de Trânsito (1998) mostra que é possível mudar o comportamento no trânsito e convida à elaboração e execução de programas de redução de acidentes. Apesar de ele ter introduzido uma disciplina muito maior no trânsito, produzindo, em consequência, uma redução nos índices de mortalidade, necessita de ações coadjuvantes provenientes de uma política pública adequada que envolva, por meio da educação no trânsito, uma mudança cultural profunda no sentido de transformar motoristas e pedestres em cidadãos mais conscientes em relação aos seus direito e deveres ${ }^{4}$. Estudo de Bastos, Andrade e Cordoni Junior constatou redução de 12,3 e 18,5\% do número de acidentes e de vítimas, em períodos de três meses cada, anteriores e posteriores à implantação do novo Código Nacional de Trânsito em Londrina, $\mathrm{PR}^{5}$. Esses autores também demonstraram uma redução do número de acidentes e de vítimas nas primeiras semanas de implantação do novo código, com recrudescimento nas duas últimas semanas do período de estudo, que durou de 22 de janeiro a 21 de abril de 1998. Em outro estudo realizado em Londrina, Liberatti, Andrade e Soares encontraram, em períodos antes e depois da implantação do novo código, um aumento do uso do cinto de segurança de 45 para 62,6\%, do uso de capacete de 31,2 para $66,2 \%$, redução do número de motoristas com menos de 18 anos e redução da presença de hálito etílico entre motociclistas ${ }^{6}$.

Conhecer, com maior detalhamento possível, como esses eventos ocorrem é indispensável para que ações de prevenção específicas possam ser planejadas e postas em prática. Dessa forma, ao fazer uma análise descritiva das sequelas decorrentes de acidentes de trânsito, objeto de estudo ainda pouco explorado na literatura, poder-se-á alertar a população dos perigos e riscos existentes, além de fortalecer as campanhas de prevenção.

\section{Métodos}

Estudo epidemiológico transversal e retrospectivo.

Foram analisados todos os laudos de lesões corporais de vítimas de acidente de trânsito correspondentes ao período de janeiro a dezembro de 2006, totalizando 377 . Os critérios de inclusão adotados foram laudos de lesão corporal efetuados após exame de vítimas de acidente de trânsito de ambos os sexos que receberam atendimento do Instituto Médico Legal (IML) Estácio de Lima no ano de 2006, enquanto os critérios de exclusão foram prontuários incompletos, cujo laudo ainda aguardava definição ou a identificação do paciente estava incompleta.

As variáveis primárias estimadas da pesquisa foram: tipo de sequela (debilidade permanente, enfermidade incurável, deformidade permanente, perda ou inutilização do membro, sentido ou função) mecanismo de trauma, condição da vítima (pedestre, condutor, passageiro), gravidade das lesões. As variáveis secundárias foram: sexo, idade.

No que tange às sequelas, a debilidade permanente foi incluída como um enfraquecimento evidente de caráter funcional, um estado já consolidado; a enfermidade incurável como um processo de evolução variável e que repercute sobre todo o organismo; a deformidade permanente como um dano estético irreparável pelos meios comuns, ou por si mesmo, capaz de provocar sensação de repulsa no observador; e a perda ou inutilização do membro, sentido ou função, uma contingência mais séria que acarreta um dano em grau máximo em sua funcionalidade ${ }^{7}$.

As lesões corporais, consideradas quanto à quantidade e à qualidade do dano, foram classificadas como leves, graves e gravíssimas segundo o aspecto jurídico das gravidades das lesões. As lesões leves eram aquelas representadas por danos de pouquíssima repercussão orgânica ou por perdas superficiais, de fácil recuperação individual. As lesões graves eram aquelas das quais resultou incapacidade para as ocupações habituais por mais de 30 dias; perigo de vida; debilidade permanente de membro, sentido ou função; e aceleração do parto. Já as lesões gravíssimas eram aquelas das quais resultou incapacidade permanente para o trabalho; enfermidade incurável; perda ou inutilização de membro, sentido ou função; deformidade permanente; e aborto ${ }^{7}$.

Os dados foram documentados e a classificação adequada foi realizada pelos autores com base nas lesões descritas detalhadamente nos laudos. 
O resultado encontrado foi consequente à análise quantitativa baseada em frequência absoluta e proporções das notificações colhidas no arquivo do IML Estácio de Lima no período de janeiro a dezembro de 2006 depois de adequada classificação quanto ao aspecto jurídico das gravidades das lesões.

\section{Resultados}

Foram analisados 377 laudos de lesões corporais, correspondentes ao período de janeiro a dezembro de 2006. Dos laudos estudados, $48,8 \%$ das vítimas apresentaram sequelas (Gráfico 1). As vítimas investigadas caracterizaram-se por serem, em sua maioria, jovens e adultos jovens $(56,8 \%)$, conforme Gráfico 2. O sexo masculino correspondeu a $76,9 \%$ de vítimas com sequelas, conforme o Gráfico 3. O maior número de acidentes foram os automobilísticos correspondendo a 77,7\% (Gráfico 4). A maioria dos acidentes teve lesões graves (35\%), sendo que destas $53 \%$ tiveram algum tipo de sequela. As lesões leves representaram 34,7\% e as gravíssimas, $30,3 \%$. As sequelas foram agrupadas em quatro grupos: debilidade permanente (DbP), que correspondeu a $49 \%$, deformidade permanente (DfP), 37\%, enfermidade incurável (EI), 6\%, e perda ou inutilização do membro, sentido ou função (PIMSF), $8 \%$.

\section{Discussão}

O número de incapacitados por acidentes de trânsito tem aumentado significativamente. Entre as explicações para esse fenômeno observa-se: a) maior número de acidentes de trânsito entre jovens que apresentam melhores condições de saúde para sobreviver aos acidentes graves; b) maior velocidade dos veículos; c) aumento do número de veículos pesados; d) avanços nas técnicas médicas de ressuscitamento ${ }^{1}$. A Organização Pan-Americana da Saúde (OPS) estima que a cada adolescente que morre por acidente de trânsito, entre 10 a 15 apresentam sequelas graves, $\mathrm{e}$ de 30 a 40 sofrem ferimentos graves, devendo utilizar serviços de emergência e/ou reabilitação ${ }^{8}$. Ao traçar o perfil epidemiológico, concluímos que, do total de laudos pesquisados, 48,8\% das vítimas tiveram algum tipo de sequela, sendo a Dbp responsável por 49\% dos casos, Dfp, 37\%, EI, 6\%, e PIMSF, $8 \%$.

As lesões graves (35\%) e gravíssimas $(30,3 \%)$ tiveram significativa importância no estudo apresentado. Isso só comprova a representatividade dos acidentes de trânsito como problemas de saúde pública. Suas implicações trazem graves prejuízos ao indivíduo (financeiros, familiares, de locomoção, profissionais etc.) e para a sociedade (gastos hospitalares, diminuição de produção, custos previdenciários etc.). As estimativas da OPS

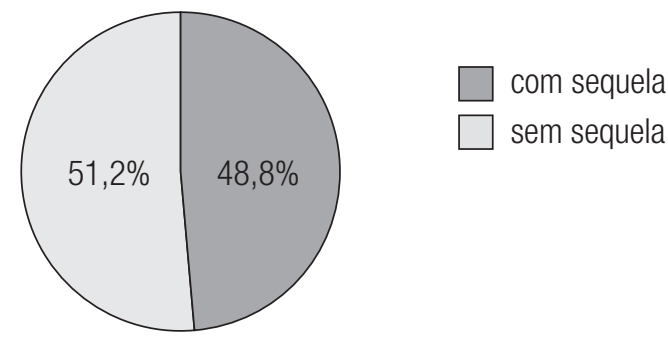

Gráfico 1: Distribuição dos pacientes vítimas de acidente de trânsito quanto à presença ou ausência de sequela. Instituto Médico Legal Estácio de Lima, Maceió (AL)

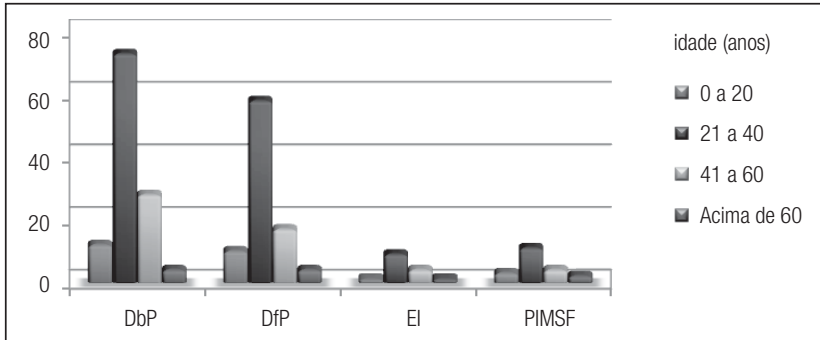

Dbp: debilidade permanente; Dfp: deformidade permanente; El: enfermidade incurável; PIMS: perda ou inutilização do membro, sentido ou função.

Gráfico 2: Distribuição do número de pacientes vítimas de acidente de trânsito, que apresentavam determinada sequela, e sua faixa etária. Instituto Médico Legal Estácio de Lima, Maceió (AL)

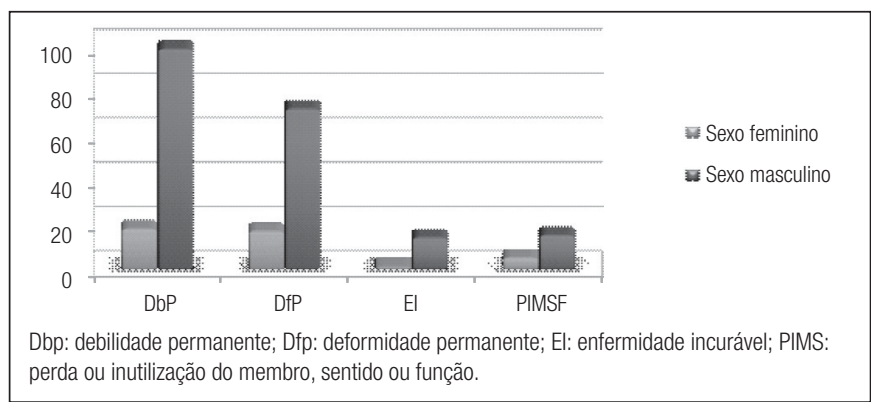

Gráfico 3: Distribuição do número de pacientes vítimas de acidente de trânsito que apresentavam determinada sequela e seu sexo. Instituto Médico Legal Estácio de Lima, Maceió (AL)

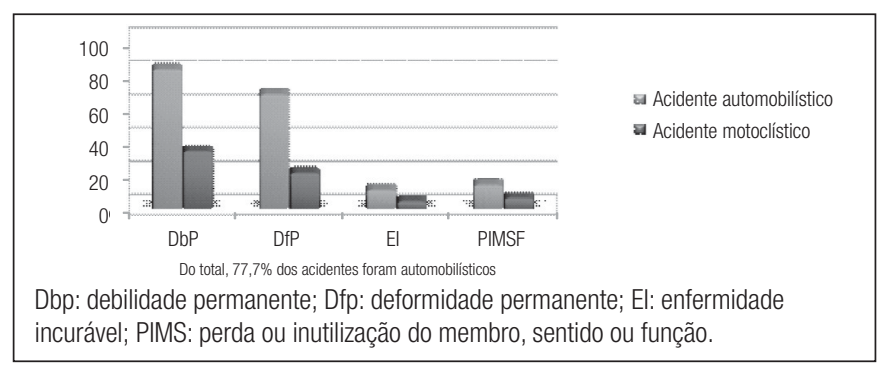

Gráfico 4: Distribuição do número de pacientes vítimas de acidente de trânsito que apresentavam determinada sequela e o mecanismo de trauma envolvido. Instituto Médico Legal Estácio de Lima, Maceió(AL) 
apontam que $6 \%$ das deficiências físicas no mundo são causadas por acidente de trânsito. No Brasil, do total de portadores de deficiências atendidos pelo Hospital das Clínicas de São Paulo, 5,5\% são casos de vítimas de acidente de trânsito?.

As vítimas investigadas caracterizaram-se por serem, em sua maioria, adultos jovens $(56,8 \%)$, do sexo masculino $(76,9 \%)$, dados corroborados em muitos trabalhos da literatura. Braga Júnior, por exemplo, em seu trabalho, mostra que, provavelmente, essefenômeno venha ocorrendo, devido ao fato desse grupo ser responsável pelo desenvolvimento de atividades mais ativas e desafiadoras. Acrescenta que esse problema pode estar relacionado à imprudência e inconsequência dessa faixa etária, impulsionada muitas vezes por uma personalidade empreendedora diretamente relacionada com atividades perigosas, representando um risco na promoção de acidentes ${ }^{10}$. Quanto à explicação para o diferencial por sexo, observado para quase todas as faixas etárias, vários estudos relacionam à maior inserção do homem no mercado de trabalho, acarretando maior exposição em decorrência à atividade profissional e ao trajeto para o trabalho ${ }^{11}$. Murray e Lopez, ao analisarem a mortalidade no sexo masculino, utilizando o cálculo de anos potenciais de vida perdidos (APVP), observaram que os acidentes de trânsito constituem a segunda causa de morte precoce no mundo todo. Em alguns países, os óbitos por acidente de trânsito entre homens de 15 a 24 anos representam metade ou mais das mortes por todas as causas, havendo uma diminuição após os 25 anos de idade ${ }^{12}$.

Em se tratando do tipo de colisão, verificou-se maior incidência dos acidentes automobilísticos $(77,7 \%)$, enquanto os motociclísticos representaram $22,3 \%$ do total. Tais estatísticas diferem do que diz Oliveira e Sousa em seu trabalho ${ }^{13}$. Segundo eles, a proporção de feridos em acidentes de motocicleta é bem maior que naqueles envolvidos em acidentes de trânsito com outros veículos a motor. Estudos realizados em algumas cidades de médio porte revelaram que os motociclistas prevalecem entre as outras categorias das vítimas de acidentes de trânsito, porém os percentuais variam de um local para outro, sendo que em algumas cidades chegam a atingir valores próximos de $50 \%{ }^{13,14}$. No município de São Paulo, Gawryszewski e Mello Jorge referem que os óbitos decorrentes de acidentes de motocicleta não aparecem como importantes nas estatísticas oficiais e afirmam que tal fato pode estar relacionado à má qualidade dos registros ${ }^{15,16}$. Não foi possível caracterizar estatisticamente os atropelamentos, já que tal informação não constava nos laudos.

\section{Conclusão}

A elevada incidência de acidentes de trânsito representa um problema de saúde pública em todo o mundo. Os acidentes fatais correspondem a apenas uma parte do problema, tendo grande destaque aqueles que acarretam sequelas incapacitantes e os que evoluem para recuperação total, mas levam a um período de afastamento laboral ou acadêmico, fator que traz grandes custos para a sociedade.

A partir deste trabalho foi possível traçar o perfil das vítimas de acidentes de trânsito e analisar suas sequelas. Do ponto de vista da Saúde Coletiva, tal estudo contribuiu com mais dados epidemiológicos que possam servir de base para a avaliação da situação dos acidentes de trânsito e o planejamento das ações e dos serviços no sentido de buscar uma mudança das normas de segurança no trânsito, assim como alertar a população da importância da prevenção.

\section{Referências Bibliográficas}

1. Marin L, Queiroz MS. A atualidade dos acidentes de trânsito na era da velocidade: uma visão geral. Cad. Saúde Pública. 2000;16(1):7-21.

2. Longo MC, Hunter CE, Lokan RJ, White JM, White MA. The prevalence of alcohol, cannabinoids, benzodiazepines and stimulants amongst injured drivers and their role in driver culpability. Parte II: the relationship between drug prevalence and drug concentration, and driver culpability. Accid Anal Prev. 2000;32(5):623-32

3. Sá CP. Representações sociais: o estado atual da teoria. In: Spink MJ (Org.). O Conhecimento no Cotidiano (Spink, M.J., org.) São Paulo: Brasiliense; 1993. p.19-45.

4. Shibata A, Fukuda K. Risk factors of fatality in motor vehicle traffic accidents. Accid Anal Prev. 1994;(26):391-7.

5. Bastos YGL, Andrade SM, Cordoni Jr L. Acidentes de trânsito e o novo código de trânsito brasileiro em cidade da região sul do Brasil. Inf Epidemiol SUS. 1999;(2):37-45.

6. Liberatti CLB, Andrade SM, Soares DA. The new Brazilian traffic code and some characteristics of victims in southern Brazil. Inj Prev. 2001;7(3):190-3.

7. França GV. Medicina legal. Rio de Janeiro: Guanabara Koogan S.A.; 2001.

8. Organización Panamericana de la Salud (OPS), 1994. Las Condiciones de Salud en las Américas. Washington, D.C.: OPS.

9. Governo do Estado de São Paulo. Prevenção de Deficiências: Segurança no Trânsito. [Dissertação]. São Paulo: Programa Estadual de Atenção à Pessoa Portadora de Deficiência/Secretaria da Saúde/ Secretaria de Transportes; 1993.

10. Braga Jr MB, Chagas Neto FA, Porto MA, Barroso TA, Lima ACM, Silva $\mathrm{SM}$, et al. Epidemiologia e grau de satisfação do paciente vítima de trauma músculo-esquelético atendido em hospital de emergência de rede pública brasileira. Acta Ortop Bras. 2005;(13):137-40.

11. Duarte CMR. Perfil de mortalidade no Município do Rio de Janeiro. Saúde em Debate, 1993;(40):60-7.

12. Murray CJL, Lopez AD. The global burden of disease in 1990: final results and their sensitivity to alternative epidemiological perspectives, discount rates, age weights and disability weights. In: Murray CJL, Lopes AD (Ed.). The Global Burden of Disease: A Comprehensive Assessment of Mortality and Disability for Diseases, Injuries, and Risk Factors in 1990 and Projected to 2020. Cambridge: Harvard University Press/World Health Organization/ World Bank; 1996. p. 247-94.

13. Oliveira NLB, Sousa RMC. Diagnóstico de lesões e qualidade de vida de motocicletas, vítimas de acidentes de trânsito. Rev. Latino-Am Enfermagem. 2003;11(6):749-56.

14. Scalassara MB, de Souza RK, Soares DF. Características da mortalidade por acidentes de trânsito em localidade da Região Sul do Brasil. Rev. Saúde Pública. 1998;(32):125-32.

15. Mello Jorge MHP. Mortalidade por causas violentas no município de São Paulo, Brasil. Rev. Saude Publica. 1980;(14):475-508.

16. Gawryszewski VP, Mello Jorge MHP. Mortalidade violenta no município de São Paulo: um retrato dos últimos 40 anos. Rev Bras Epidemiologia. 2000;(1/3):50-69. 